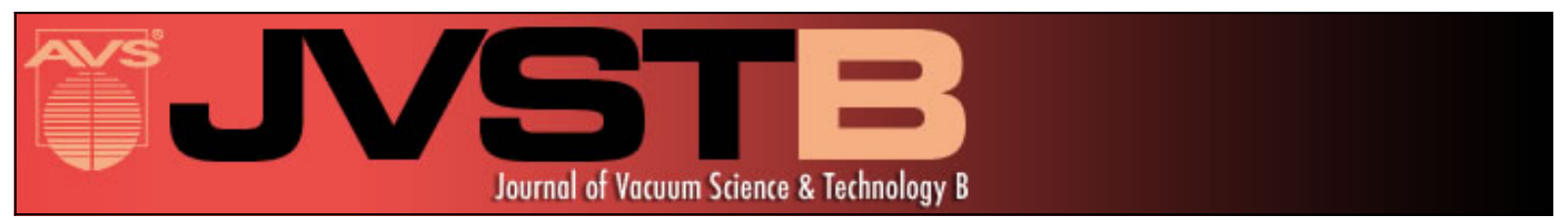

\title{
Strain-balanced InAs/InAs1-xSbx type-II superlattices grown by molecular beam epitaxy on GaSb substrates
}

Elizabeth H. Steenbergen, Kalyan Nunna, Lu Ouyang, Bruno Ullrich, Diana L. Huffaker, David J. Smith, and Yong-Hang Zhang

Citation: Journal of Vacuum Science \& Technology B 30, 02B107 (2012); doi: 10.1116/1.3672028

View online: http://dx.doi.org/10.1116/1.3672028

View Table of Contents: http://scitation.aip.org/content/avs/journal/jvstb/30/2?ver=pdfcov

Published by the AVS: Science \& Technology of Materials, Interfaces, and Processing

\section{Articles you may be interested in}

Impact of substrate temperature on the structural and optical properties of strain-balanced InAs/InAsSb type-II superlattices grown by molecular beam epitaxy

Appl. Phys. Lett. 102, 071903 (2013); 10.1063/1.4793231

CdSe/CdTe type-Il superlattices grown on GaSb (001) substrates by molecular beam epitaxy

Appl. Phys. Lett. 100, 121908 (2012); 10.1063/1.3697676

Structural properties of InAs/InAs1-xSbx type-II superlattices grown by molecular beam epitaxy

J. Vac. Sci. Technol. B 30, 02B106 (2012); 10.1116/1.3672026

Structural and optical characterization of type-II InAs/InAs1-xSbx superlattices grown by metalorganic chemical vapor deposition

Appl. Phys. Lett. 99, 071111 (2011); 10.1063/1.3625429

Lateral diffusion of minority carriers in $\mathrm{n} \mathrm{Bn}$ based type-II InAs/GaSb strained layer superlattice detectors

Appl. Phys. Lett. 93, 123507 (2008); 10.1063/1.2990049

\section{SHIMADZU Powerful, Multi-functional UV-Vis-NIR and Excellence in Science FTIR Spectrophotometers}

Providing the utmost in sensitivity, accuracy and resolution for applications in materials characterization and nano research

- Photovoltaics - Ceramics

- Polymers - DNA film structures

- Thin films - Coatings

- Paints - Packaging materials
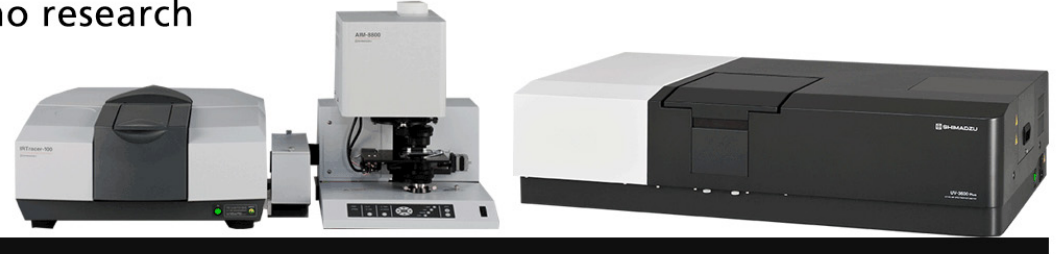


\title{
Strain-balanced InAs/lnAs ${ }_{1-x} S_{b}$ type-Il superlattices grown by molecular beam epitaxy on GaSb substrates
}

\author{
Elizabeth H. Steenbergen \\ Center for Photonics Innovation and School of Electrical, Computer and Energy Engineering, \\ Arizona State University, Tempe, Arizona 85287 \\ Kalyan Nunna \\ California NanoSystems Institute, University of California, Los Angeles, California 90095 \\ Lu Ouyang \\ Department of Physics, Arizona State University, Tempe, Arizona 85287 \\ Bruno Ullrich \\ Air Force Research Lab, Materials \& Manufacturing Directorate, Wright Patterson AFB, Ohio 45433-7707 \\ Diana L. Huffaker \\ California NanoSystems Institute, University of California, Los Angeles, California 90095 \\ David J. Smith \\ Department of Physics and Center for Photonics Innovation, Arizona State University, Tempe, Arizona 85287 \\ Yong-Hang Zhanga) \\ Center for Photonics Innovation and School of Electrical, Computer and Energy Engineering, Arizona State \\ University, Tempe, Arizona 85287
}

(Received 26 October 2011; accepted 3 December 2011; published 21 December 2011)

\begin{abstract}
Strain-balanced InAs/InAs ${ }_{1-x} \mathrm{Sb}_{\mathrm{x}}$ type-II superlattices (SLs) on GaSb substrates with $0.27 \leq \mathrm{x} \leq 0.33$ were grown by molecular beam epitaxy and demonstrated photoluminescence (PL) up to $11.1 \mu \mathrm{m}$. The calculated SL bandgap energies agree with the PL peaks to within $5 \mathrm{meV}$ for long-wavelength infrared samples $(9.5,9.9$, and $11.1 \mu \mathrm{m})$ and to within $9 \mathrm{meV}$ for a mid-wavelength infrared sample $(5.9 \mu \mathrm{m})$. X-ray diffraction measurements reveal average SL mismatches of less than $0.2 \%$, and the PL full-width-at-half-maximums increase with the mismatch, confirming the importance of strain-balancing for material quality. (C) 2012 American Vacuum Society. [DOI: 10.1116/1.3672028]
\end{abstract}

\section{INTRODUCTION}

Antimonide-based type-II superlattices (T2SLs) have many potential advantages over bulk $\mathrm{HgCdTe}$ for infrared photodetector materials, ${ }^{1}$ with the InAs/(In)GaSb T2SL being the most investigated. However, short minority carrier lifetimes $^{2,3}$ in InAs/(In)GaSb T2SLs are detrimental to the detector dark current and quantum efficiency ${ }^{4}$ and have recently been partially attributed to acceptorlike defects in $\mathrm{GaSb}^{2}$ rather than the interfaces. ${ }^{5}$ With $\mathrm{Ga}$ being the suspected culprit of the short minority carrier lifetime, the $\mathrm{Ga}$-free InAs/InAs $\mathrm{s}_{1-\mathrm{x}} \mathrm{Sb}_{\mathrm{x}}$ T2SL has the potential for longer lifetimes. The "stabilized Fermi level" due to intrinsic point defects in bulk InAs is expected to be above the conduction band edge, ${ }^{6}$ rendering any midgap defect states inactive for Shockley-Read-Hall (SRH) processes. In comparison, the stabilized Fermi level for bulk GaSb is expected to be in the bandgap near the valence band edge, ${ }^{6}$ leaving the midgap states available for SRH recombination. Relatively high photoluminescence (PL) efficiencies for $4-11 \mu \mathrm{m}$ emission from InAs/InAs ${ }_{1-x} \mathrm{Sb}_{\mathrm{x}}$ T2SLs grown on GaAs with highly dislocated $1 \mu \mathrm{m} \mathrm{InAsSb}$ buffer layers also suggest that As-rich $\operatorname{InAs}_{1-x} \mathrm{Sb}_{\mathrm{x}}$ alloys have comparatively low SRH

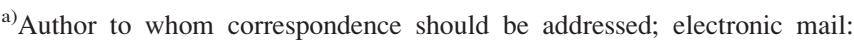
yhzhang@asu.edu
}

recombination coefficients. ${ }^{7}$ A minority carrier lifetime of $250 \mathrm{~ns}$ reported for bulk $\mathrm{InAs} \mathrm{s}_{0.80} \mathrm{Sb}_{0.20}$ having a PL peak at $5.4 \mu \mathrm{m}$ at $77 \mathrm{~K}^{2}$ further supports the possibility that the InAs/InAs ${ }_{1-x} \mathrm{Sb}_{\mathrm{x}} \mathrm{T} 2 \mathrm{SLs}$ may have longer lifetimes than those of the InAs/(In)GaSb T2SLs. Theoretically calculated absorption of an $11 \mu \mathrm{m} \mathrm{InAs/InAs}{ }_{1-x} \mathrm{Sb}_{\mathrm{x}}$ T2SL was lower, but within a factor of two, than that of a $10 \mu \mathrm{m}$ InAs/ (In)GaSb T2SL. ${ }^{8}$ The theoretical study did not include SRH recombination, leaving open the possibility that in practice, the former T2SL may have higher absorption and a longer minority carrier lifetime than the latter due to interface and growth-related variations. ${ }^{8}$

Although not as well studied as InAs/(In)GaSb T2SLs, $\operatorname{InAs}_{1-\mathrm{x}} \mathrm{Sb}_{\mathrm{x}} / \mathrm{InAs}_{1-\mathrm{y}} \mathrm{Sb}_{\mathrm{y}}$ T2SLs have been investigated by several groups since their first proposal, which proposed utilizing tensile strain to reach longer wavelengths than bulk $\mathrm{InAs}_{1-\mathrm{x}} \mathrm{Sb}_{\mathrm{x}}$, to possibly compete with HgCdTe. ${ }^{9} \mathrm{InAs}_{1-\mathrm{x}} \mathrm{Sb}_{\mathrm{x}} /$ $\mathrm{InAs}_{1-\mathrm{y}} \mathrm{Sb}_{\mathrm{y}}$ SLs were grown by both molecular beam epitaxy (MBE) and metalorganic chemical vapor deposition (MOCVD) with complicated strain-relieving buffer layers: (1) on InSb for LWIR $(8-12 \mu \mathrm{m})$ photodetectors, ${ }^{10,11}$ (2) on InAs for MWIR lasers, ${ }^{12-14}$ (3) on GaAs for LWIR LEDs, ${ }^{7,15}$ and (4) on GaSb for LWIR photodetectors. ${ }^{16-18}$ However, the growth of InAs/InAs ${ }_{1-\mathrm{x}} \mathrm{Sb}_{\mathrm{x}}$ T2SLs on GaSb by MBE has not yet been reported. This article reports the design, MBE growth, and characterization of a set of strain-balanced InAs/ 
$\mathrm{InAs}_{1-\mathrm{x}} \mathrm{Sb}_{\mathrm{x}}$ T2SLs on GaSb substrates for MWIR and LWIR detectors.

\section{MODELING}

InAs/InAs ${ }_{1-\mathrm{x}} \mathrm{Sb}_{\mathrm{x}}$ T2SLs can be strain balanced on GaSb by choosing appropriate combinations of layer thicknesses and $\mathrm{InAs}_{1-\mathrm{x}} \mathrm{Sb}_{\mathrm{x}}$ alloy compositions. In order to achieve high quality materials with low misfit dislocation densities, the critical thicknesses ${ }^{19}$ of InAs and $\operatorname{InAs}_{1-\mathrm{x}} \mathrm{Sb}_{\mathrm{x}}$ on GaSb are used as the limits for the layer thicknesses in the strainbalanced T2SL designs. The zero-stress method, ${ }^{20}$ which takes the elastic constants of the layers into account, is used to calculate the strain-balanced layer thicknesses. A threeband envelope function approximation model, ${ }^{21}$ which includes coupling between the electrons, light holes, and spin-orbit split-off holes, is used to calculate the T2SL effective bandgap defined as the electron to heavy hole transition energy. The InAs, InSb, and $\mathrm{InAs}_{1-\mathrm{x}} \mathrm{Sb}_{\mathrm{x}}$ parameters are taken from Ref. 22. Recent studies using the type-IIb (electron well in the binary layer) alignment have found the bowing of the InAs${ }_{1-x} \mathrm{Sb}_{\mathrm{x}}$ valence band to be between $60-70 \%$ of the bandgap bowing. ${ }^{18,23,24}$ The calculations presented here use the type-IIb alignment with $65 \%$ of the $\operatorname{InAs}_{1-\mathrm{x}} \mathrm{Sb}_{\mathrm{x}}$ bandgap bowing attributed to the valence band.

Figure 1 displays the calculated T2SL bandgap versus the layer thicknesses for strain-balanced designs on $\mathrm{GaSb}$ for three different InAs ${ }_{1-\mathrm{x}} \mathrm{Sb}_{\mathrm{x}}$ compositions. Within this composition range $(\mathrm{x} \sim 0.25-0.38)$, the $\mathrm{InAs} / \mathrm{InAs}_{1-\mathrm{x}} \mathrm{Sb}_{\mathrm{x}}$ T2SL is shown to cover the MWIR and LWIR ranges. For a given composition, thicker layers result in smaller bandgaps, and the overlap between the electron and heavy-hole wave functions decreases. However, as the absorption coefficient is proportional to the square of the wave function overlap (and the density of states), larger overlaps are desirable. To optimize the wave function overlap for a particular bandgap, as shown in Fig. 2, the layers should be thin with higher $\mathrm{Sb}$ compositions in the $\mathrm{InAs}_{1-\mathrm{x}} \mathrm{Sb}_{\mathrm{x}}$ layer. The wave function

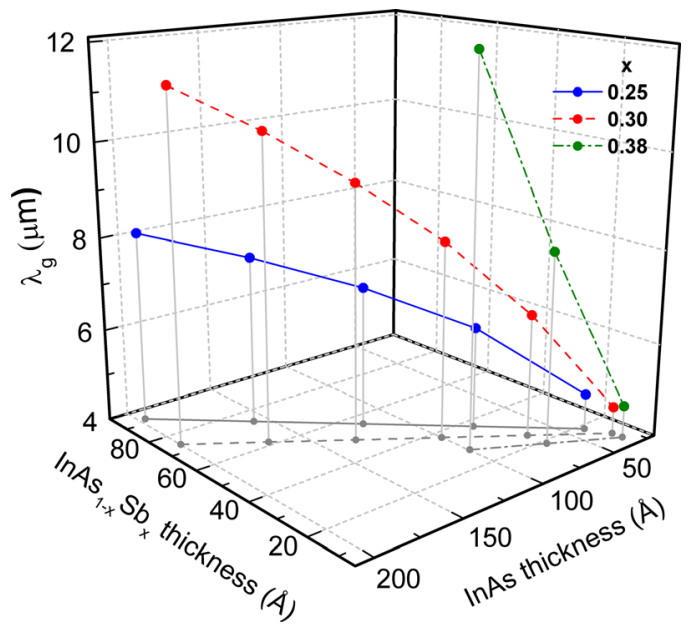

FIG. 1. (Color online) Calculated effective bandgaps for strain-balanced InAs/InAs ${ }_{1-x} \mathrm{Sb}_{\mathrm{x}}$ type-II superlattices on GaSb substrates for three different $\mathrm{Sb}$ compositions.

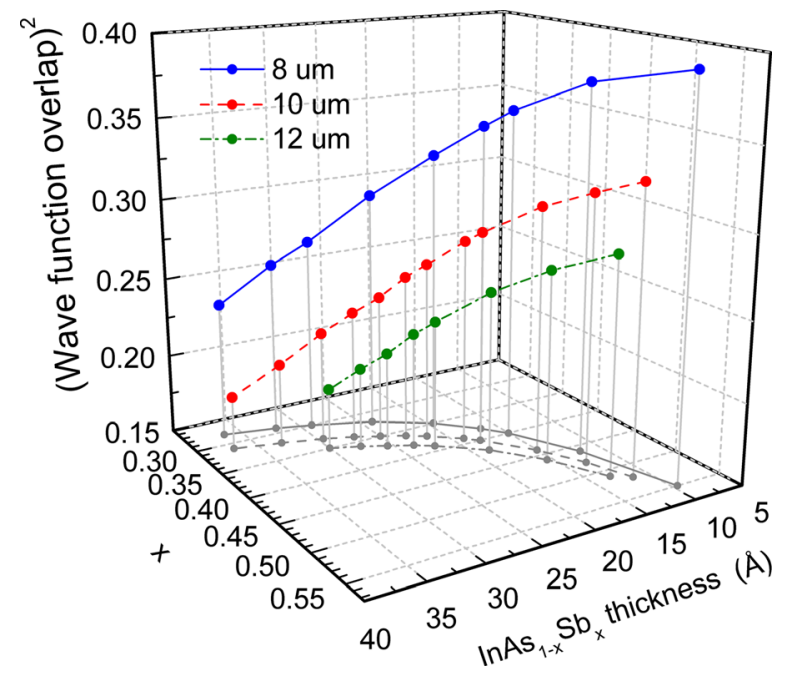

FIG. 2. (Color online) Calculated square of the electron-heavy-hole wave function overlap for different strain-balanced $\mathrm{InAs} / \mathrm{InAs}_{1-\mathrm{x}} \mathrm{Sb}_{\mathrm{x}}$ type-II superlattice designs having bandgaps at 8,10 , and $12 \mu \mathrm{m}$.

overlap is inherently lower for the longer wavelength designs due to the higher $\mathrm{Sb}$ compositions resulting in larger valence band offsets and increased heavy-hole confinement.

\section{EXPERIMENT}

\section{A. Molecular beam epitaxy growth}

Several InAs/InAs ${ }_{1-\mathrm{x}} \mathrm{Sb}_{\mathrm{x}}$ T2SLs designs were grown on $n$ GaSb substrates by solid source MBE equipped with valved crackers set up to produce $\mathrm{As}_{2}$ and $\mathrm{Sb}_{2}$ species. Following the oxide desorption at $530^{\circ} \mathrm{C}$, a GaSb buffer layer was grown at $500^{\circ} \mathrm{C}$. The substrate was then cooled to $435^{\circ} \mathrm{C}$ for the

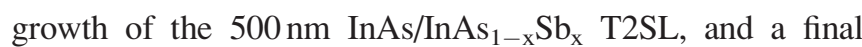
$\mathrm{GaSb}$ cap layer was grown at $480^{\circ} \mathrm{C}$. Four samples A, B, C, and $\mathrm{D}$ with 20 period SLs were grown under identical conditions with varying $\mathrm{Sb} /(\mathrm{As}+\mathrm{Sb})$ beam equivalent pressure (BEP) flux ratios. The nonunity sticking coefficient of the group-V materials, As and $\mathrm{Sb}$, and their competition for incorporation makes it difficult to control the group- $\mathrm{V}$ composition. However, by changing only the As flux and keeping all the remaining elements identical, a systematic variation in the $\mathrm{Sb}$ incorporation can be achieved. Thus, the $\operatorname{InAs}_{1-\mathrm{x}} \mathrm{Sb}_{\mathrm{x}}$ layers in samples $\mathrm{A}, \mathrm{B}, \mathrm{C}$, and $\mathrm{D}$ have $\mathrm{Sb} /(\mathrm{As}+\mathrm{Sb}) \mathrm{BEP}$ ratios of $0.32,0.347,0.378$, and 0.412 , respectively. Sample E consists of $60 \mathrm{~T} 2 \mathrm{SL}$ periods with an overall thickness of $500 \mathrm{~nm}$ and $10 \mathrm{~nm}$ undoped AlSb barriers on either side of the overall T2SL to increase the PL intensity.

\section{B. Characterization}

The actual T2SL periods and $\operatorname{InAs}_{1-x} \mathrm{Sb}_{\mathrm{x}}$ compositions were determined from the shutter times and the simulations of (004) $\omega-2 \theta$ coupled high-resolution XRD patterns recorded with a PANalytical X'Pert Pro MRD. The simulations use pseudomorphically strained layers on the GaSb substrate, which is reasonable given the results from a (224) reciprocal space map for sample $\mathrm{B}$ : only $0.2 \%$ relaxation and $\mathrm{x}$ differing by only 0.004 from the (004) $\omega-2 \theta$ scan value. Transmission 
electron microscopy (TEM) characterization was carried out using a JEM-4000EX high-resolution electron microscope operated at $400 \mathrm{keV}$ with a structural resolution of $\sim 1.7 \AA$. The samples were prepared for observation along $\{110\}$-type zone-axis projections so that the direction of the electron beam would be aligned perpendicular to the growth surface normal. The PL measurements were carried out at $5 \mathrm{~K}$ using a continuous-wave $532 \mathrm{~nm}$ solid-state laser modulated at $60 \mathrm{kHz}$ with an excitation intensity of $105 \mathrm{~W} / \mathrm{cm}^{2}$. The PL spectra were taken using a double-modulation technique with a Fourier transform infrared spectrometer to suppress the room temperature blackbody radiation.

\section{RESULTS AND DISCUSSION}

\section{A. X-ray diffraction}

The (004) $\omega-2 \theta$ measurement and simulation results for the sample structure parameters are summarized in Table I, including the average T2SL mismatch with the substrate and the zero-order T2SL peak FWHM. The mismatch and FWHM for samples C and D are in italics to denote the zeroorder T2SL peak position was calculated, due to its overlap with the substrate peak, based on the period and the T2SL satellite peak positions and that the FWHM is the mean of all the T2SL satellite peaks' FWHMs. Figure 3 shows the (004) $\omega-2 \theta$ profiles for samples B, C, and D. The relatively large T2SL period of $25 \mathrm{~nm}$ causes some envelope function modulation of the T2SL satellite peak intensities, reflecting the strain of the individual InAs and $\operatorname{InAs}_{1-x} \mathrm{Sb}_{\mathrm{x}}$ layers, on the right and left of the substrate peak, respectively. These modulations result in the most intense T2SL peak no longer corresponding to the T2SL zero-order peak. The average T2SL mismatch in the growth direction is net tensile and less than $0.2 \%$ for all the samples, with sample D being the most closely lattice-matched to GaSb at $0.03 \%$. Figure 4 shows the XRD data and simulation for sample E. The smaller T2SL period of sample $\mathrm{E}$ is evident from the greater T2SL satellite peak spacing.

\section{B. Transmission electron microscopy}

Cross-section electron micrographs of the different samples generally revealed well-defined SL layers and sharp

TABLE I. Summary of the InAs/InAs ${ }_{1-\mathrm{x}} \mathrm{Sb}_{\mathrm{x}}$ T2SL structures.

\begin{tabular}{lccccc}
\hline \hline Sample & $\begin{array}{c}\mathrm{X} \\
\pm 0.01\end{array}$ & $\begin{array}{c}\text { Period } \\
\pm 0.5 \\
(\mathrm{~nm})\end{array}$ & $\begin{array}{c}\text { Number of } \\
\text { periods }\end{array}$ & $\begin{array}{c}\text { XRD SL0 } \\
\text { mismatch } \\
(\mathrm{ppm})\end{array}$ & $\begin{array}{c}\text { XRD SL0 peak } \\
\text { FWHM } \\
(\operatorname{arcsec})\end{array}$ \\
\hline $\begin{array}{l}\text { A } \\
(0203-1)\end{array}$ & 0.27 & 26.5 & 20 & -1930 & 55 \\
$\mathrm{~B}$ & 0.28 & 24.6 & 20 & -1754 & 35 \\
$(0218-1)$ & & & & & \\
$\mathrm{C}$ & 0.29 & 24.6 & 20 & -1164 & 39 \\
$(0218-2)$ & & & 20 & -279 & 41 \\
$\mathrm{D}$ & 0.33 & 24.5 & 20 & \\
$(0218-3)$ & & & & -2231 & 92 \\
$\mathrm{E}$ & 0.30 & 7.4 & 60 & & \\
$(0512-1)$ & & & & & \\
\hline \hline
\end{tabular}

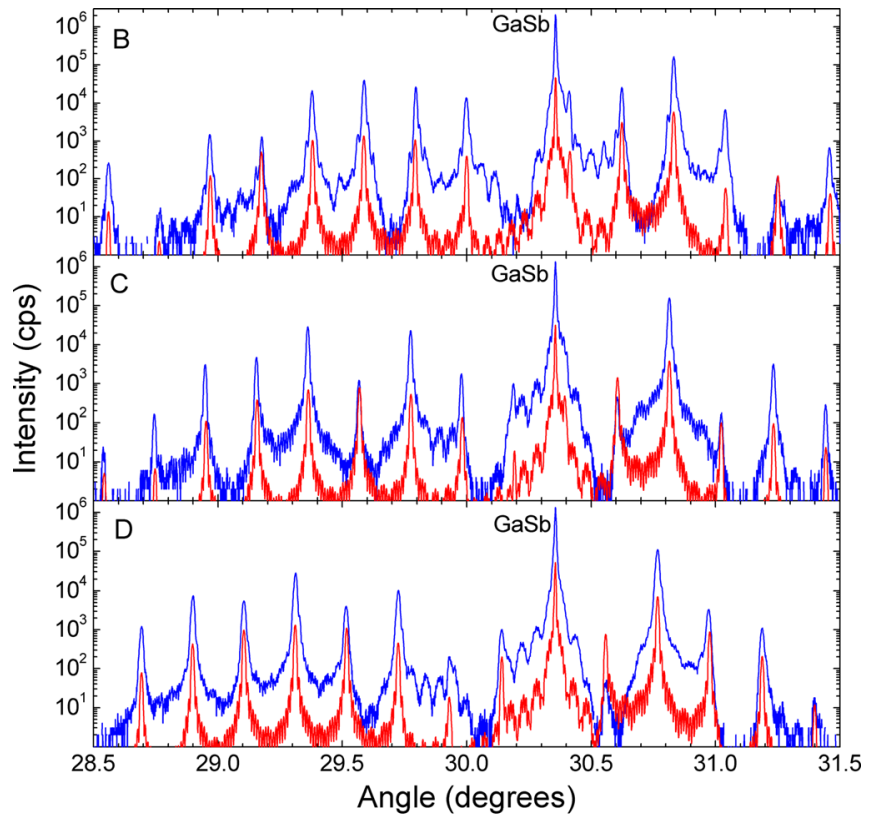

FIG. 3. (Color online) High-resolution $\omega-2 \theta \times$ ray diffraction patterns and simulations (offset below the data) for the (004) reflection of InAs/ $\mathrm{InAs}_{1-\mathrm{x}} \mathrm{Sb}_{\mathrm{x}}$ type-II superlattice samples $\mathrm{B}, \mathrm{C}$, and D.

interfaces, although some growth defects, mostly $\{111\}$ type stacking defects, were also visible in some places. The low-magnification TEM image of sample B, as shown in Fig. 5, reveals smooth interfaces and some defects, most starting at the substrate/buffer layer interface. A T2SL periodicity of $24.5 \mathrm{~nm}$ is measured, in very good agreement with the period from the XRD measurement. TEM images of sample A did not show evidence of dislocations, indicating the defect density is lower than that in sample B. Further details about TEM used to investigate the microstructure of InAs/InAs ${ }_{1-x} \mathrm{Sb}_{\mathrm{x}}$ T2SLs with ordered and random In $\mathrm{As}_{1-\mathrm{x}} \mathrm{Sb}_{\mathrm{x}}$ alloy layers grown by modulated and conventional MBE, respectively, are reported in a separate paper in this proceeding. ${ }^{25}$

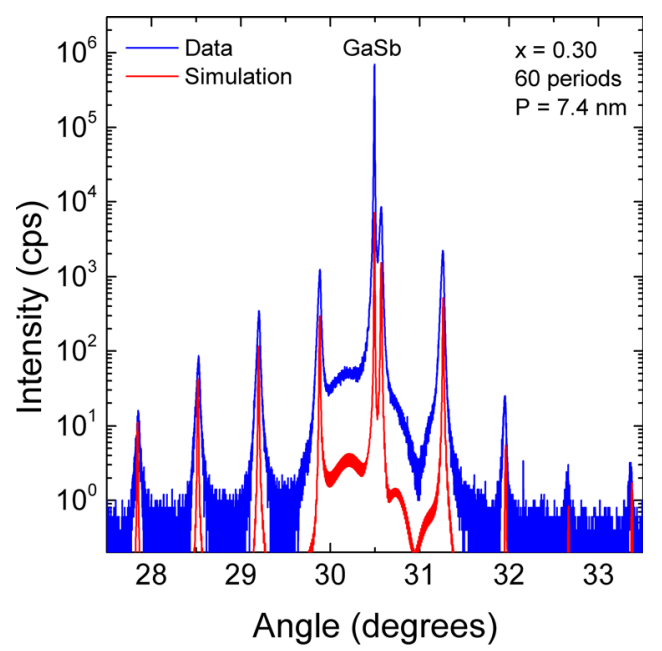

FIG. 4. (Color online) High-resolution $\omega-2 \theta \times$ ray diffraction pattern and simulation (offset below the data) for the (004) reflection of sample E. 


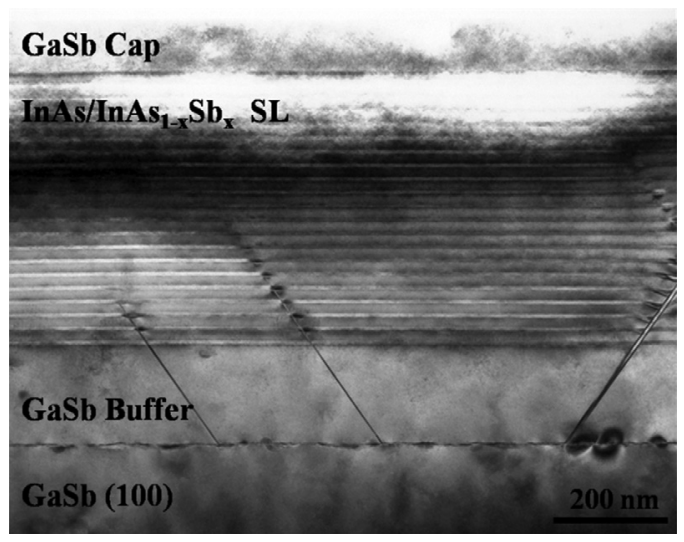

FIG. 5. Cross-sectional transmission electron micrograph showing typical defect microstructure of sample B which mostly consisted of $\{111\}$-type stacking faults originating at the $\mathrm{GaSb}$ (buffer)/GaSb substrate interface.

\section{Photoluminescence}

PL results for samples A, B, C, and E are shown in Fig. 6 with the symbols representing the data and the solid lines an eight-point adjacent-average smoothing of the data. Gaussian fits were applied, and the peak positions and FWHMs are shown in Table II. PL from sample D was not measurable. LWIR samples A, B, and C having similar periods confirm the expected trend of longer wavelength transitions for increasing Sb compositions. The PL intensity for sample B is approximately half that of samples A and C despite the similar emission wavelengths and wave function overlaps. This is presumably due to the greater number of dislocations originating at the substrate/buffer layer interface as shown in the TEM for sample B in Fig. 5. Sample E, with a significantly shorter period, results in MWIR emission that is more intense than the LWIR samples' emission due to the much higher wave function overlap and the AlSb electron barriers.

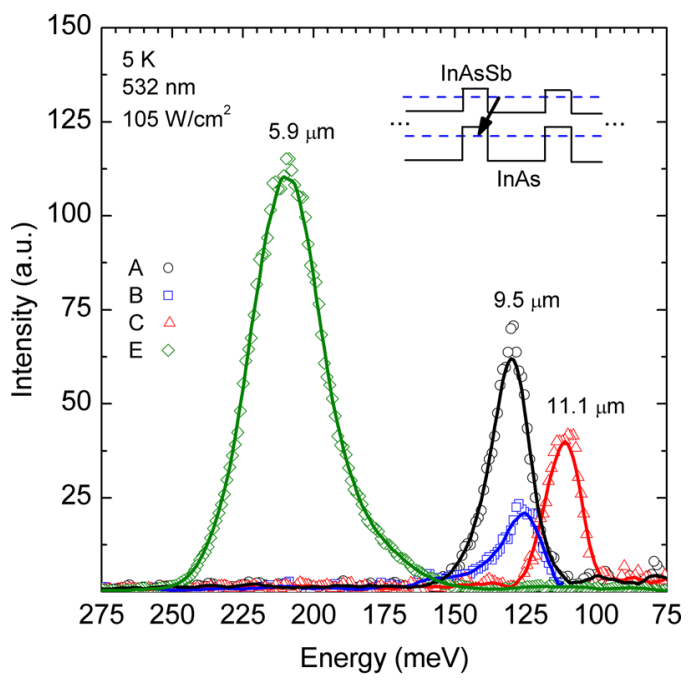

FIG. 6. (Color online) Photoluminescence spectra at $5 \mathrm{~K}$ for InAs/ $\mathrm{InAs}_{1-\mathrm{x}} \mathrm{Sb}_{\mathrm{x}}$ type-II superlattice samples $\mathrm{A}, \mathrm{B}, \mathrm{C}$, and $\mathrm{E}$ with varying compositions and periods. The data (symbols) are smoothed with eight-point adjacent-averaging (solid lines). The inset shows a schematic of the SL band alignment and PL transition.
TABLE II. Summary of the InAs/InAs ${ }_{1-x} \mathrm{Sb}_{\mathrm{x}}$ T2SL calculated bandgaps and PL results.

\begin{tabular}{|c|c|c|c|c|}
\hline Sample & $\begin{array}{c}\text { Calculated } \\
\text { bandgap at } 0 \mathrm{~K} \\
(\mathrm{meV} / \mu \mathrm{m})\end{array}$ & $\begin{array}{l}\text { PL peak location } \\
\text { at } 5 \mathrm{~K}(\mathrm{meV} / \mu \mathrm{m})\end{array}$ & $\begin{array}{c}\text { PL peak } \\
\text { FWHM } \\
(\mathrm{meV})\end{array}$ & $\begin{array}{l}\text { Calculated } \\
\left|\int \Psi_{h h}^{*} \Psi_{e} d z\right|^{2} \\
(\%)\end{array}$ \\
\hline $\begin{array}{l}\text { A } \\
(0203-1)\end{array}$ & $128 / 9.7$ & $130 / 9.5$ & 18 & 6.1 \\
\hline $\begin{array}{l}\text { B } \\
(0218-1)\end{array}$ & $120 / 10.4$ & $125 / 9.9$ & 17 & 7.0 \\
\hline $\begin{array}{l}\text { C } \\
(0218-2)\end{array}$ & $107 / 11.6$ & $112 / 11.1$ & 14 & 6.6 \\
\hline $\begin{array}{l}\text { D } \\
(0218-3)\end{array}$ & $72 / 17.1$ & - & - & 5.6 \\
\hline $\begin{array}{l}\mathrm{E} \\
(0512-1)\end{array}$ & $218 / 5.7$ & 209/5.9 & 33 & 45.2 \\
\hline
\end{tabular}

The agreement between the calculated SL bandgaps and PL peaks is quite remarkable given the uncertainty in the material parameters and band offsets used in the calculation and in the measured $\mathrm{Sb}$ compositions and periods. The 14-18 meV FWHMs for samples A, B, and C correspond well with the $15-20 \mathrm{meV}$ calculated bandgap shift results for $\mathrm{a} \pm 0.01$ change in $\mathrm{x}$, whereas the layer thickness fluctuation barely affects the calculated bandgap due to the large SL period. Sample E, however, with a much smaller period and a $33 \mathrm{meV}$ FWHM, experiences an approximately $30 \mathrm{meV}$ bandgap shift for a \pm 1 monolayer $\operatorname{InAs}_{1-\mathrm{x}} \mathrm{Sb}_{\mathrm{x}}$ thickness change but only $\sim 15 \mathrm{meV}$ for \pm 0.01 change in $\mathrm{x}$. The PL peak FWHMs also follow the same tendency as the XRD average SL mismatch, a wider FWHM for a larger mismatch, demonstrating the correlation between strainbalancing and the SL material quality. Thus, strainbalancing is extremely important to avoid dislocations and achieve device quality SL materials.

\section{SUMMARY AND CONCLUSIONS}

In summary, strain-balanced InAs/InAs ${ }_{1-x} \mathrm{Sb}_{\mathrm{x}}$ type-II SLs with $0.27 \leq x \leq 0.33$ were grown by molecular beam epitaxy and demonstrated photoluminescence spectra out to $11.1 \mu \mathrm{m}$, giving good agreement between the calculated SL bandgaps and photoluminescence peak positions. Transmission electron microscopy, along with $\mathrm{x}$ ray diffraction, and photoluminescence spectra line widths have shown the importance of strain-balancing to achieve high optical material quality with minimal dislocations. These findings indicate clearly that the InAs/InAs ${ }_{1-x} \mathrm{Sb}_{\mathrm{x}}$ type-II SL is an excellent candidate for MWIR and LWIR device applications.

\section{ACKNOWLEDGMENTS}

This paper is based upon work supported in part by the U. S. Army Research Laboratory and the U. S. Army Research Office MURI program under Grant No. W911NF10-1-0524 and Air Force Office of Scientific Research Grant No. (FA9550-10-1-0129). PL experiments were performed at AFRL/RXPS with the support of G. Brown. E.H.S. appreciates the DOD SMART and SFAz scholarships and 
acknowledges the ASU Office of the Vice-President for Research and Economic Affairs, the Graduate Research Support Program, and the Graduate College.

${ }^{1}$ D. R. Rhiger, J. Electron. Mater. 40, 1815 (2011).

${ }^{2}$ G. Belenky, G. Kipshidze, D. Donetsky, S. P. Svensson, W. L. Sarney, H. Hier, L. Shterengas, D. Wang, and Y. Lin, Proc. SPIE 8012, 80120W (2011).

${ }^{3}$ B. C. Connelly, G. D. Metcalfe, H. Shen, and M. Wraback, Appl. Phys. Lett. 97, 251117 (2010).

${ }^{4}$ S. Bandara, P. Maloney, N. Baril, J. Pellegrino, and M. Tidrow, Infrared Phys. Technol. 54, 263 (2011).

${ }^{5}$ S. P. Svensson, D. Donetsky, D. Wang, P. Maloney, and G. Belenky, Proc. SPIE 7660, 76601V (2010).

${ }^{6}$ W. Walukiewicz, Proc. Mat. Res. Soc. Symp. 148, 137 (1989).

${ }^{7}$ P. J. P. Tang, M. J. Pullin, S. J. Chung, C. C. Phillips, R. A. Stradling, A. G. Norman, Y. B. Li, and L. Hart, Semicond. Sci. Technol. 10, 1177 (1995).

${ }^{8}$ C. H. Grein, M. E. Flatte and H. Ehrenreich, in Proceedings on the Third International Symposium on Long Wavelength Infrared Detectors and Arrays: Physics and Applications III, Chicago, IL, 8-13 October 1995 (The Electrochemical Society, Inc., Pennington, NJ 1995), p. 211

${ }^{9}$ G. C. Osbourn, J. Vac. Sci. Technol., B 2, 176 (1984).

${ }^{10}$ S. R. Kurtz, L. R. Dawson, R. M. Biefeld, I. J. Fritz, and T. E. Zipperian, IEEE Electron Device Lett. 10, 150 (1989).

${ }^{11}$ R. M. Biefeld, S. R. Kurtz, and S. A. Casalnuovo, J. Cryst. Growth 124, 401 (1992).

${ }^{12}$ Y.-H. Zhang, "Mid-Wave Infrared InAs/InAsSb Type-II Superlattice Lasers" for "Strained Quantum Wells and their Applications," Optoelectrical
Properties of Semiconductor Quantum Wells and Superlattices (Gorden and Breach, Amsterdam, The Netherlands, 1997).

${ }^{13}$ S. R. Kurtz, R. M. Biefeld, A. A. Allerman, A. J. Howard, M. H. Crawford, and M. W. Pelczynski, Appl. Phys. Lett. 68, 1332 (1996).

${ }^{14}$ P. J. P. Tang, M. J. Pullin, Y. B. Li, C. C. Phillips, R. A. Stradling, S. J. Chung, W. T. Yuen, L. Hart, D. J. Bain, and I. Gaibraith, Appl. Phys. Lett. 69, 2501 (1996).

${ }^{15}$ Y. B. Li, D. J. Bain, L. Hart, M. Livingstone, C. M. Ciesla, M. J. Pullin, P. J. P. Tang, W. T. Yuen, I. Galbraith, C. C. Phillips, C. R. Pidgeon and R. A. Stadling, Phys. Rev. B 55, 4589 (1997).

${ }^{16}$ Y. Huang, J.-H. Ryou, R. D. Dupuis, V. R. D'Costa, E. H. Steenbergen, J. Fan, Y.-H. Zhang, A. Petschke, M. Mandl, and S.-L. Chuang, J. Cryst. Growth 314, 92 (2011).

${ }^{17}$ S. R. Kurtz, L. R. Dawson, R. M. Biefeld, D. M. Follstaedt and B. L. Doyle, Phys. Rev. B 46, 1909 (1992).

${ }^{18}$ D. Lackner, O. J. Pitts, M. Steger, A. Yang, M. L. W. Thewalt, and S. P. Watkins, Appl. Phys. Lett. 95, 081906 (2009).

${ }^{19}$ J. W. Matthews and A. E. Blakeslee, J. Cryst. Growth 27, 118 (1974).

${ }^{20}$ N. Ekins-Daukes, K. Kawaguchi, and J. Zhang, Cryst. Growth Des. 2, 287 (2002).

${ }^{21}$ F. Szmulowicz, E. R. Heller, K. Fisher, and F. L. Madarasz, Superlattices Microstruct. 17, 373 (1995).

${ }^{22}$ I. Vurgaftman, J. R. Meyer, and L. Ram-Mohan, J. Appl. Phys. 89, 5815 (2001).

${ }^{23}$ P.-W. Liu, G. Tsai, H. H. Lin, A. Krier, Q. D. Zhuang, and M. Stone, Appl. Phys. Lett. 89, 201115 (2006).

${ }^{24}$ C.-J. Wu, G. Tsai, and H.-H. Lin, Appl. Phys. Lett. 94, 211906 (2009).

${ }^{25}$ L. Ouyang, E. H. Steenbergen, Y.-H. Zhang, K. Nunna, D. L. Huffaker, and D. J. Smith, "Structural properties of InAs/InAs ${ }_{1-x}$ Sbx type-II superlattices grown by molecular beam epitaxy," J. Vac, Sci. Technol. B (to be published). 